\title{
SOBRE PRECARIZAÇÃO, FLEXIBILIZAÇÃO E INTENSIFICAÇÃO DO TRABALHO DO EDUCADOR AMBIENTAL: PERCURSOS NA FORMAÇÃO E NA ATUAÇÃO PROFISSIONAL
}

Cláudia Lino Piccinini ${ }^{1}$

Resumo: Considerando-se o conceito de trabalho na perspectiva da economia e da sociologia do trabalho, vamos analisar trajetórias profissionais e de formação inicial e continuada - a partir de narrativas baseadas nas memórias de profissionais de educação ambiental. Buscamos relacionar escolhas profissionais, necessidades de amplificação da qualificação e inserção no mundo do trabalho. Ocorre que, em diversos casos, amplia-se a capacidade de realizar trabalho, através do aumento da especialização. Conclui-se que no transcurso de formação e de exercício profissional ocorrem diversas mudanças no tipo de trabalho realizado - educação não formal/formal - nos setores privado/público, trabalho voluntário/trabalho assalariado, ampliação dos loci de atuação, acúmulo de funções com intensificação das jornadas de trabalho, precarização e flexibilização das relações de trabalho, dentre outras.

Palavras-chave: Trabalho. Qualificação. Educação Ambiental.

\section{ABOUT PRECARIZATION, FLEXIBILIZATION AND INTENSIFICATION WORK OF ENVIRONMENTAL EDUCATORS: PATHWAYS IN TRAINING AND PROFESSIONAL PRACTICE}

Abstract: Considering the concept of work in the perspective of economy and sociology of work, let's look at career paths and training - initial and continuous, from narratives based on the memories of professional environmental education. We seek to relate career choices, needs amplification of qualification and the world of work. Occurs in many cases that expand the capacity to do work by increasing specialization in order employability. We conclude that in the course of training and professional practice several changes occur in the work - education informal / formal, private sector / public sector, volunteer / paid work, expanding the loci of activity, accumulation of functions with worsening of journeys work, flexibility and precarious of labor relations, among others.

Keywords: Work. Skills. Environmental education.

\section{ACERCA DE LA PRECARIZACIÓN, FLEXIBILIZACIÓN Y INTENSIFICACIÓN DEL TRABAJO DEL EDUCADOR AMBIENTAL: CAMINOS EN LA FORMACIÓN Y PRÁCTICA PROFESIONAL}

Resumen: Teniendo en cuenta el concepto de trabajo desde la perspectiva de la economía y la sociología del trabajo, se analizan las trayectorias y formación profesional - inicial y continuada - a partir de relatos basados en recuerdos de los

\footnotetext{
${ }^{1}$ Doutora em Educação pela Pontifícia Universidade Católica do Rio de Janeiro. Professora Adjunta II, na Universidade Federal do Rio de Janeiro, Faculdade de Educação. clpiccinini@ gmail.com
} 
profesionales de la educación ambiental. Buscamos relacionar opciones profesionales, necesidades de amplificación de cualificación e inclusión en el lugar de trabajo. Sucede que, en muchos casos, se expande la capacidad de realizar el trabajo, mediante el aumento de la especialización. Llegamos a la conclusión de que en el curso de formación y práctica profesional se producen varios cambios en el tipo de trabajo realizado - la educación no formal/oficial en los sectores público/privado, trabajo voluntario/trabajo remunerado, la ampliación de los loci de actuación, la acumulación de funciones con la intensificación de las horas de trabajo, la precarización y la flexibilización de las relaciones laborales, entre otros.

Palabras clave: Trabajo. Cualificación. Educación Ambiental.

\section{Transformações no mundo do trabalho e o trabalho do educador ambiental}

Iniciamos esta reflexão, destacando o crescimento da Educação Ambiental (EA) no Brasil. Para essa afirmação nos respaldamos tanto no aumento da produção acadêmica da área (grupos de pesquisas e volume de revistas, artigos, teses e dissertações), quanto no incremento de redes socioambientais ${ }^{2}$ e ações de EA desenvolvidas tanto no âmbito escolar ${ }^{3}$ como em diversos outros espaços educativos coletivos, salas verdes, centros de $\mathrm{EA}^{4}$.

Ressaltamos o potencial emancipador (dos sujeitos sendo capazes de conhecer para organizar a transformação) e crítico (de superação do modo de produção capitalista e dos antagonismos de classe) da educação ambiental e, consideramos fundamental compreender as transformações no mundo do trabalho, das relações sociais de produção, que afetam as ações do conjunto de atores que constituem esse grupo profissional. Partimos do suposto teórico de que a categoria trabalho é central na vida e na sociabilidade, assim como no desenvolvimento da sociedade.

Com o avanço do modo de produção capitalista intervenções no mundo do trabalho alavancaram novas formas de organização e de exploração da força de trabalho. Os trabalhadores, dentre eles os da educação, são instados a ampliar seu universo formativo para se tornarem mais adaptáveis e para que consigam ingressar ou permanecer em seus postos de trabalho.

Com a participação dos educadores ambientais, já nos anos 1990, surgem formas ideológicas de se conciliar crescimento econômico e desenvolvimento sustentável. Se, por um lado, esses educadores são chamados a se inserir na lógica produtiva, por outro, precisam lidar com a realidade socioambiental em curso, isto é, "compatibilizar expansão capitalista e utilização racional dos recursos naturais” (SILVA, 2012, p.107), "construir a cultura preservacionista, nos marcos da manutenção das relações sociais vigentes" (SILVA, 2012, p.108).

Esse profissional de novo tipo deverá enfrentar os novos desafios, dentre eles a construção dos chamados espaços educadores sustentáveis, segundo os quais, "educadoras e educadores podem mediar o processo da construção da cidadania e de

\footnotetext{
${ }^{2}$ Em 2009, eram 40 redes ligadas à Rede Brasileira de EA. (DIB-FERREIRA; GUERREIRO, 2010).

${ }^{3}$ Segundo VEIGA et al. (2005), o censo escolar do MEC/INEP de 2004 indicou que 94\% das escolas de Ensino Fundamental abordam temas ambientais no currículo.

${ }^{4}$ O Brasil possui mais de 200 Centros de Educação Ambiental. (REDE CEAS, 2004).
} 
uma cultura que adote premissas e práticas sustentáveis, aproveitando-se das ferramentas da educação ambiental". (BRASIL, s/data, p.18).

Superar as contradições na visão do materialismo histórico é compreender a educação como prática revolucionária ao mudar-se e mudar as circunstâncias, simultaneamente (MARX, 1982). Nesse sentido, estabelecemos como objetivos mapear e compreender como um grupo de educadores ambientais traçaram seus caminhos de formação e de trabalho a partir de suas narrativas pessoais. Narrativas construídas a partir das memórias sobre suas trajetórias pessoais, que nos informam sobre escolhas e possibilidades de ação profissional e apontam, também, as barreiras para a consolidação de uma EA que se materialize como esfera contra hegemônica.

\title{
20 significado do trabalho no universo do capitalismo contemporâneo
}

[...] Com a 'valorização' do mundo das coisas, aumenta em proporção direta a 'desvalorização' do mundo dos homens [...]. Marx e Engels, 2005.

Segundo Lukács $(1978$, p.8), "o trabalho é um ato de pôr consciente e, portanto, pressupõe um conhecimento concreto, ainda que jamais perfeito, de determinadas finalidades e de determinados meios". É como participante (produtor) e como produto do universo do trabalho que o homem se desenvolve, se transforma.

É através do trabalho que o homem torna-se capaz de expandir seus conhecimentos, de ampliar suas possibilidades de desenvolvimento e de existência como ser natural e social, manifestando sua dimensão intelectual ${ }^{5}$, determinando a sua consciência e a sua humanidade. O trabalho é, pois, práxis produtiva - produção, autoprodução e transformação do sujeito (VÁZQUEZ, 1990).

\begin{abstract}
$\mathrm{Na}$ produção social da própria vida, os homens contraem relações determinadas, necessárias e independentes de sua vontade, relações de produção estas que correspondem a uma etapa determinada de desenvolvimento das suas forças produtivas materiais. A totalidade dessas relações de produção forma a estrutura econômica da sociedade, a base real sobre a qual se levanta uma superestrutura jurídica e política, e à qual correspondem formas sociais determinadas de consciência. O modo de produção da vida material condiciona o processo em geral de vida social, político e espiritual. Não é a consciência dos homens que determina o seu ser, mas, ao contrário, é o seu ser social que determina a sua consciência. (MARX, 1982, p.25).
\end{abstract}

O homem sempre procurou ampliar o sentido de sua vida e através da criação artística e da ação laborativa encontra elementos de humanização e de realização. A humanização se dá, por exemplo, através da conexão homem/natureza, que, ao atuar sobre ela "[...] modifica ao mesmo tempo, sua própria natureza (...). No fim do processo de trabalho obtém-se um resultado que já no início deste existiu na imaginação do trabalhador, e portanto idealmente" (MARX, 1982, p.150).

\footnotetext{
5 Todo trabalho é trabalho intelectual não importando sua complexidade ou sua simplicidade, todo trabalho possui uma dimensão imanentemente intelectual (GRAMSCI, 2004). Será através da divisão social do trabalho, que um indivíduo assumirá ou não a tarefa de intelectual. Logo, o intelectual está sujeito às diferenças oriundas da luta de classes.
} 
$\mathrm{Na}$ análise do conceito e dos atributos do trabalho no universo contemporâneo sobressaem novas formas de controle e o estabelecimento de um novo significado para o conceito de trabalho. Para o sociólogo Richard Sennett (2004), o modelo reconhecido como capitalismo flexível mantém as bases do trabalho no velho sistema opressor capitalista, mas com uma nova roupagem baseada em novas tecnologias, em novas formas de organização do tempo do trabalho, na especialização flexível da produção e na descentralização das responsabilidades. O autor afirma que a "ênfase na flexibilidade está mudando o próprio significado do trabalho" (SENNETT, 2004, p. 9). As influências principais para o cotidiano do trabalhador se materializam na fragmentação do trabalho, do senso de comunidade e de família; no sentimento de deriva, entendido como risco ou fracasso; na falsa sensação de liberdade; na mobilidade acentuada por postos de trabalho e no paralelo aumento do tempo exigido no trabalho, com o cumprimento de metas de curto prazo; no medo de perder o controle de suas vidas; no individualismo, nas relações descartáveis e no preconceito. Trata-se do trabalho em uma sociedade baseada na reprodução social, na valorização e acumulação do capital, cujos efeitos se materializam na degradação social e ambiental.

Nesse sentido, o capital opera de modo inexorável e articuladamente ao processo de acumulação: em um só movimento aprofunda a exploração do trabalho humano, promove o desemprego, a precarização das relações de trabalho, a redução dos direitos sociais e de igual maneira intensifica a dilapidação ambiental [...]. (SILVA, 2012, p.108).

O trabalho a curto prazo, por contrato ou episódico, descrito por Sennett (2004), exige do novo trabalhador projetos pessoais também de curto prazo. Estar constantemente submetido a mudanças exige do trabalhador rápida adaptação às circunstâncias dos postos de trabalho, à ambiguidade e às suas incertezas. Ao mesmo tempo em que certas qualificações e habilidades específicas constituem justificativas para o ingresso ou exclusão no mercado de trabalho (grau de empregabilidade), a possibilidade de construção de uma carreira e a consolidação obtida através das experiências de uma vida de trabalho parecem não mais importar.

Atualmente, vivemos o aumento da produção de bens, assim como do fornecimento de serviços. Por um lado, temos o avanço da superespecialização do trabalho, bancada pelos ramos tecnológicos, no outro lado da mesma moeda, o avanço da terceirização, que supõe baixo grau de complexidade e, por consequência, remuneração menor em relação aos que possuem vínculos trabalhistas. Isso é o que denominamos de trabalho precarizado ${ }^{6}$ (ANTUNES, 2008, p.1-2). Não bastasse "o processo além da precarização estrutural do trabalho, os capitais globais estão exigindo também o desmonte da legislação social protetora do trabalho". (ANTUNES, 2008, p.8).

A flexibilização das leis que protegem o trabalhador é usada como meio para amenizar o desemprego e os problemas sociais dele derivados.

\footnotetext{
${ }^{6} \mathrm{O}$ conceito de precarização, foco de disputas dentre os estudiosos do trabalho (LEITE, 2008), reflete a deterioração das condições de trabalho que afeta a toda a classe trabalhadora, evidenciando uma nova gestão sobre a força de trabalho, identificado pela diminuição da remuneração (ou por sua imprevisibilidade), pela divisão dos trabalhadores (temporários, prestadores de serviços, subcontratados etc.), por mudanças nas jornadas de trabalho, perda de direitos trabalhistas, dentre outros aspectos.
} 
Ao discutir a categoria trabalho neste modelo objetivamos conhecer as bases das relações de produção que vão condicionar a formação e o trabalho de educador ambiental nas suas várias possibilidades e que vão diretamente conformar a sociedade onde se inserem. Pois, consideramos que o acirramento das relações de produção no universo do trabalho tem alterado a vida social, política e a subjetividade dos trabalhadores.

\section{0 grupo profissional: breve perfil, trajetórias e inserção no trabalho}

Os educadores ambientais, enquanto grupo organizado, ${ }^{7}$ tiveram seu primeiro reconhecimento do ponto de vista internacional em 1975, em Belgrado, durante o I Encontro Internacional de Educação Ambiental, onde se criou o Programa Internacional de Educação Ambiental. Nesse contexto se inserem os educadores que estudamos neste artigo.

Os sujeitos da pesquisa foram localizados através de anais de congressos nacionais e regionais. O primeiro contato foi realizado via e-mail, quando também foram apresentados os objetivos da pesquisa. O pedido de envio de memorial, já previamente confeccionado, foi atendido por 30 sujeitos. Desse universo, apenas 22 foram selecionados por atenderem ao perfil, isto é, atuarem profissionalmente como educadores ambientais.

Os memoriais, nossa fonte de pesquisa, são documentos que narram a trajetória formativa e laboral dos educadores. Tratamos os memoriais como fonte histórica.

O memorial, um escrito onde alguém conta e reflete sobre a sua vida, depende do grau de implicação de cada participante, do desejo e da capacidade de fazer memória de sua vida e de significar vivências no espaço; assim, constitui-se em uma história de vida. (BASTOS, 2003, p.169).

A análise dos documentos se baseou na teoria da enunciação de Mikhail Bakhtin (2003), onde os enunciados são considerados como acontecimentos dialógicos, isto é, como posições singulares e de natureza sócio-histórica.

Então, revelou-se que no grupo preponderam as educadoras, são 17 mulheres e apenas 5 representantes do sexo masculino. Essa diferença numérica nos leva a uma comparação a partir do universo do trabalho, visto que 17 profissionais exercem ou exerceram em algum momento de sua trajetória a profissão docente (em espaços formais de ensino), historicamente relacionada com a atuação feminina (MIGNOT, 2003). Entretanto, apesar da maioria feminina, dos cinco representantes masculinos quatro também exercem função docente, 3 no ensino superior e 1 na educação básica. A grande maioria (18) trabalha e reside nos estados do sudeste, especificamente: 12 no Rio de Janeiro capital, 4 no interior do estado de São Paulo e 2 em Vitória-ES. Temos uma representante do Mato Grosso do Sul, dois representantes do Rio Grande do Sul (interior) e uma do estado do Acre. Apesar da abrangência (4 regiões do país), há a concentração nos estados do sudeste, representando os limites da coleta de dados ou a concentração de trabalhos de EA nessa região.

\footnotetext{
7 Destacamos que, apesar de sua constituição ampla, da heterogeneidade dos sujeitos que chamamos de educadores ambientais, há uma categoria educadores ambientais. Corroboram essa tese, os trabalhos de Guimarães (2004) e de Sanchez (2008), dentre outros.
} 
A faixa etária dos educadores ambientais está compreendida entre duas representantes de 30 e de 65 anos. Há um educador com cerca de 55 anos, 12 educadores têm entre 45 - 50 anos e 7 entre 35 - 42 anos. A diversidade etária forneceu certa abrangência temporal, por exemplo, com trabalhadores de trajetória consolidada, com muita história para contar.

Quanto a aspectos da escolaridade, interessou estabelecer se esses educadores passaram por algum tipo de formação pré-universitária diferenciada do Ensino Médio regular, isto é, se haviam cursado o normal médio ou algum curso técnico, o que poderia indicar o início de uma carreira mesmo antes da universidade. Dentre os 8 memoriais que fizeram referência à passagem pela escola, uma educadora indicou ter cursado o Técnico em Química concomitante ao Ensino Médio, e 3 educadores passaram pelo curso normal médio, sendo um do sexo masculino. Aponto que quatro memoriais citam a passagem pelo Ensino Médio regular.

Em relação ao item principal ocupação atual em atividade remunerada verifico que 3 não possuíam emprego fixo no momento da redação dos memoriais, estando expostos a um regime de contratação temporária e de caráter esparso. Destes, dois revelam ocupação eventual no terceiro setor, em Organizações Não Governamentais (ONGs). Os demais ocupam 25 atividades distribuídas entre a educação formal (15 educadores) e não formal (10 educadores). Dos educadores que mantém ocupação na educação formal ${ }^{8}$, assim se distribuem quantitativamente pela educação superior e básica:

Tabela 1 - Distribuição dos educadores ambientais com ocupação atual na educação formal

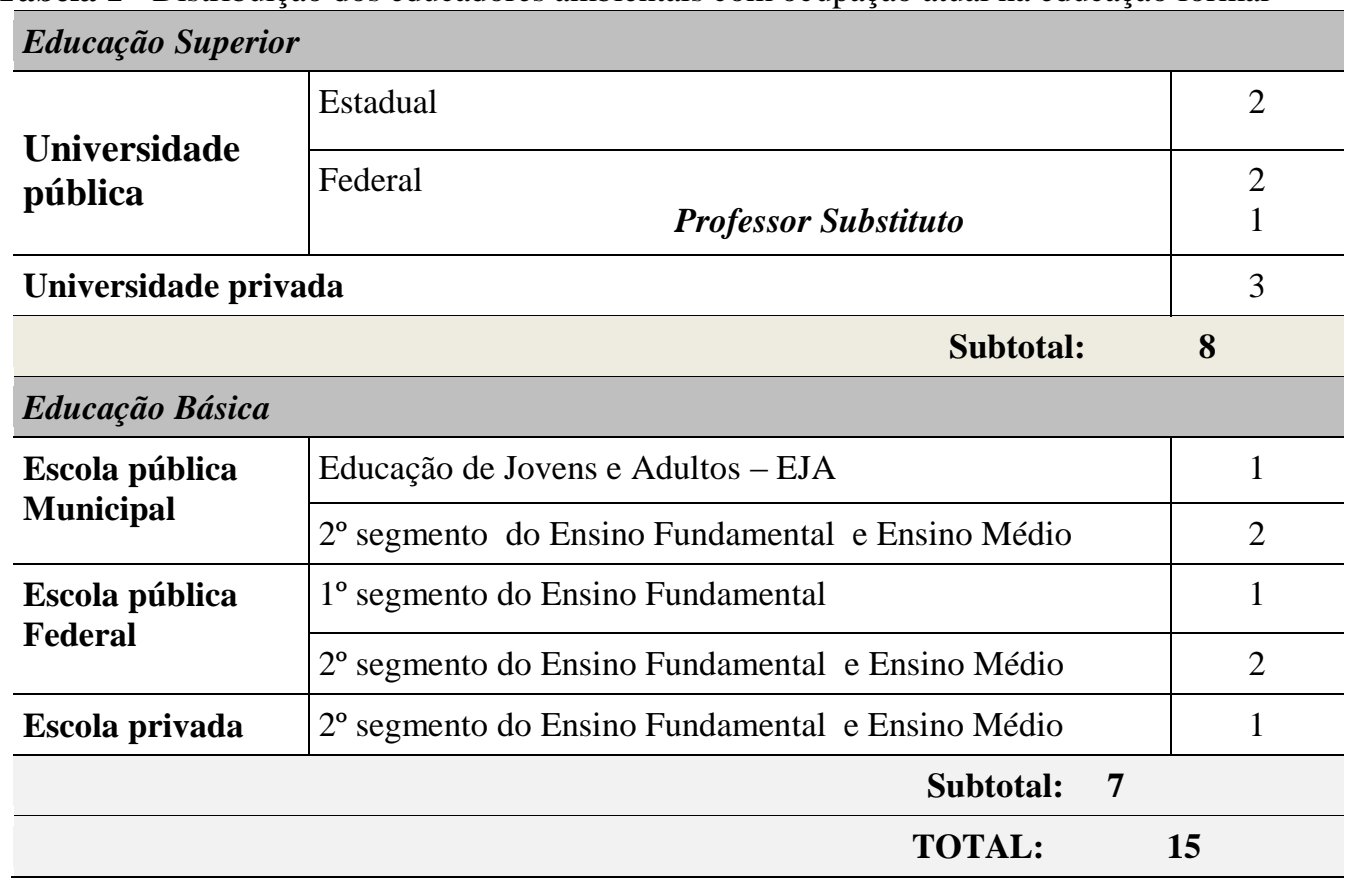

\footnotetext{
${ }^{8}$ Segundo a Lei 9.795 de abril de 1999 - Seção II - Da Educação Ambiental no Ensino Formal, Art.9 (BRASIL, 1999), entende-se por educação ambiental na educação escolar desenvolvida no âmbito dos currículos das instituições de ensino público e privado, englobando:

I - educação básica:

a) educação infantil; b) ensino fundamental; c) ensino médio;

II - educação superior;

III - educação especial;

IV - educação profissional

$\mathrm{V}$ - educação de jovens e adultos.
} 
No grupo de educadores que trabalham na educação pública municipal temos uma que também pertence ao quadro da Secretaria Municipal de Educação, nível central, acumulando função em um Centro de Educação Ambiental.

Consideram-se como modalidades educativas também as atividades relacionadas com a educação não formal, relatadas por 10 educadores ambientais. Podemos caracterizar a educação não formal a partir do enunciado de uma educadora que se dedica a apresentar as diferentes modalidades de educação.

\begin{abstract}
[...] alguns conceitos, sobre os quais não deteremos maiores análises, explicitam seus diferentes modos de efetivação como uma característica fundamental da conceituação de educação, denominando-os de: erudito/ formal (numa alusão ao ensino escolar, em sala de aula) e o não-formal (descrito para todos os tipos de público), em diferentes espaços possíveis para se praticar a compreensão - englobando os sentidos de discussão, reflexão, racionalização, conceituação - e transformação da realidade (MEMORIAL 12).
\end{abstract}

Na tabela 2 demonstramos onde atuam os trabalhadores que se dedicam ao ensino não formal. Destacando que, em quatro casos, há acumulação em postos de trabalho no ensino formal.

Tabela 2 - Distribuição dos educadores ambientais com ocupação atual na educação não formal

\begin{tabular}{l|l|c}
\hline \multirow{2}{*}{ Serviço público } & \multicolumn{1}{c}{$\mathbf{1}$} \\
\hline \multirow{2}{*}{ Federal } & Fundação da área de Saúde (Fiocruz) & $\mathbf{2}$ \\
\cline { 2 - 3 } & Instituto de Meio Ambiente (IBAMA) & $\mathbf{1}$ \\
\hline Municipal & Secretaria Estadual de Meio Ambiente (RS) & $\mathbf{1}$ \\
\hline \multicolumn{2}{|c}{ Secretaria Municipal de Meio Ambiente (Vitória) } \\
\hline Contrato precário de trabalho & $\mathbf{1}$ \\
\hline Fundação Federal da área de Saúde (Fiocruz) & $\mathbf{3}$ \\
\hline Organizações Não-Governamentais & $\mathbf{1}$ \\
\hline Órgãos públicos em parceria com ONGs Subtotal: & $\mathbf{5}$ \\
\hline & \multicolumn{1}{c}{ Total: } \\
\hline
\end{tabular}

Como demonstram as tabelas 1 e 2 há registros de atividades baseadas na prestação temporária e ocasional de serviços (a exemplo do professor com contrato de substituto), ou seja, há trabalhadores que não sendo absorvidos formalmente pelo sistema produtivo, estão à mercê de ampla gama de atividades para garantirem sua sobrevivência, conforme descrito no memorial de uma educadora com 10 anos de experiência:

Na área de Meio Ambiente (...) tive experiências de trabalho das mais variadas, que acho importante citar algumas: educação ambiental formal e não-formal; relações com a comunidade; estudos e avaliações de impactos ambientais (meio antrópico); audiências públicas (organização, coordenação e realização executiva); planejamento em educação ambiental; 
elaboração, organização e coordenação de projetos e de metodologias específicas de educação ambiental, de eventos técnicos e para a comunidade em geral; e sistematização de resultados de reuniões, seminários e pesquisas, inclusive as de conotação quali-quantitativas de opinião.

Propriamente em educação ambiental - numa designação geral a todas as citações anteriores - e em equipes interprofissionais, trabalhei junto aos setores de qualidade ambiental, saneamento básico, recursos florestais, recursos hídricos, legislação, educação ambiental à distância. (...) como prestadora de serviço por consultorias, trabalhei nas (elou para) seguintes instituições: Seama; Pref. M Vitória/Semmam; Museu Melo Leitão; Companhia Espírito-santense de Saneamento; Pref. M Serra/Secretaria de Meio Ambiente; Pref. M. Vitória/Secretaria Cultura; Futura Instituto de Pesquisas; Cepemar - Centro de Pesquisas do Mar; Pref. M. São Mateus; Citágua - Águas de Cachoeiro S/A; e Consórcio dos Rios Santa Maria da Vitória e Jucu (MEMORIAL 12 - grifo da pesquisadora).

Havendo outros registros como este nos memoriais, interessou conhecer o trânsito ao longo da carreira por ações inseridas no universo da informalidade, isto é, como contrato precário de trabalho ${ }^{9}$, apesar de reconhecer que nem sempre há um único tipo possível de relação de trabalho, ou mesmo um contrato entre o trabalhador e a instituição privada, estatal ${ }^{10}$ e/ou do chamado terceiro setor ${ }^{11}$.

No âmbito da política econômica, formalidade e informalidade, cada vez mais, constituem-se mutuamente, de sorte que trabalho formal e informal, ou precarizado e não precarizado, cada vez mais, estão combinadamente presentes nos mais diversos ramos produtivos e de serviços como é o caso, por exemplo, na educação superior. (LEITÃO DE SOUZA, 2008, p.6).

Esses são aspectos importantes para o debate, visto que, dos 22 trabalhadores, 14 têm ou tiveram em momento (s) de sua trajetória profissional uma relação desse tipo. Vejamos como se apresentou esta distribuição considerando o período compreendido desde a graduação até o último relato dos memoriais referentes ao mundo do trabalho.

Tabela 3 - Distribuição dos trabalhadores em contratos precários de trabalho.

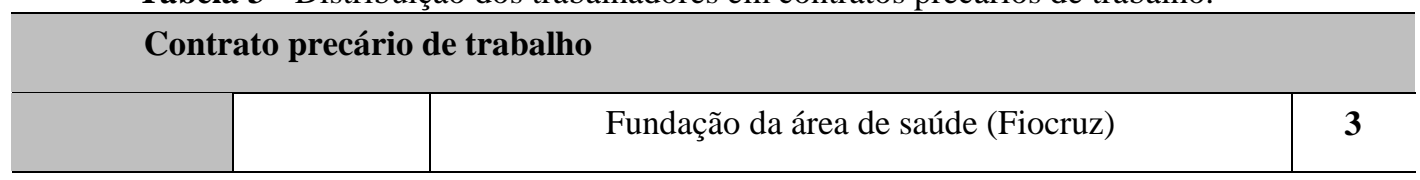

9 A chamada reestruturação produtiva contemporânea cria e determina o crescimento de inúmeras formas de subproletarização do trabalho, por exemplo, o trabalho parcial, o temporário, o trabalho domiciliar, o subcontrato e o terceirizado.

10 "O contrato de trabalho para atendimento da necessidade temporária de excepcional interesse público é aquele celebrado por uma pessoa física que, de forma pessoal, não eventual e subordinada, aliena sua força de trabalho, em caráter precário e oneroso, a ente da Administração Pública Direta, Autarquia ou Fundação Pública". No Artigo $3^{\circ}$, "O recrutamento do pessoal a ser contratado, nos termos desta Lei, será feito mediante processo seletivo simplificado sujeito a ampla divulgação, inclusive através do Diário Oficial da União, prescindindo de concurso público" (BRASIL, 1988).

11 Entende-se que "O primeiro setor é o governo, que é responsável pelas questões sociais. O segundo setor é o privado, responsável pelas questões individuais. Com a falência do Estado, o setor privado começou a ajudar nas questões sociais, através das inúmeras instituições que compõem o chamado terceiro setor. Ou seja, o terceiro setor é constituído por organizações sem fins lucrativos e não governamentais, que têm como objetivo gerar serviços de caráter público" (IBRACON, 2014). 


\begin{tabular}{|c|c|c|c|}
\hline \multirow{10}{*}{$\begin{array}{l}\text { Instituição } \\
\text { pública }\end{array}$} & \multirow{4}{*}{ Federal } & Universidades - UFRJ, UFRS, UFES & 5 \\
\hline & & INCRA & $\mathbf{1}$ \\
\hline & & Museu de Astronomia - MAST & $\mathbf{1}$ \\
\hline & & Museu Mello Leitão & 1 \\
\hline & \multirow[t]{3}{*}{ Estadual } & $\begin{array}{c}\text { Secretaria de Estado para Assuntos do Meio Ambiente de } \\
\text { Vitória }\end{array}$ & $\mathbf{1}$ \\
\hline & & $\begin{array}{l}\text { Universidade do Estado do RJ e } \\
\text { Universidade Estadual Paulista }\end{array}$ & $\begin{array}{l}2 \\
1\end{array}$ \\
\hline & & Fundação CECIERJ & $\mathbf{1}$ \\
\hline & \multirow{3}{*}{ Municipal } & $\begin{array}{c}\text { Secretaria de Meio Ambiente de São Vicente e } \\
\text { de Vitória }\end{array}$ & $\begin{array}{l}1 \\
2\end{array}$ \\
\hline & & Escola Municipal no Mato Grosso do Sul & 1 \\
\hline & & Secretaria de Educação de Vitória (escola e equipe de EA) & $\mathbf{1}$ \\
\hline \multicolumn{2}{|c|}{ Instituição privada } & Universidade Católica & 2 \\
\hline \multirow{2}{*}{\multicolumn{2}{|c|}{ Terceiro Setor }} & ONGs & 5 \\
\hline & & Fundações & 3 \\
\hline
\end{tabular}

O trabalho voluntário, que se caracteriza por não ser remunerado, também foi indicado por 8 sujeitos que, em momentos diversos de sua trajetória, se envolveram em ações de voluntariado.

\section{0 trabalho em sua relação com o processo de formação acadêmica}

Alguns educadores relataram que o ingresso na EA aconteceu a partir do trabalho. Tais ações são tão diversificadas quanto as funções ocupadas pelos trabalhadores. No exercício profissional realizam desde o desenvolvimento de projetos em escolas e parques, até a liderança de grupo de pesquisa em grandes universidades públicas, passando por consultorias e pelo trabalho voluntário.

Partindo de suas demandas de aperfeiçoamento - seja pela necessidade de aprofundar ou apreender conhecimentos, pela necessidade de ingresso no mercado de trabalho, seja por critérios de ascensão profissional baseadas no aumento da qualificação - fazem escolhas entre o desejável e o possível em termos de formação. Dessa forma, considerou-se que o trabalho assume a sua centralidade impondo demandas de formação e possibilidades de acesso e continuidade.

Nesta época senti que precisava me aprofundar mais nos estudos sobre Educação. (...) Foi esta inquietação que me levou em 1992 ao Curso de Mestrado em Educação (...). Fui buscar subsídios capazes de auxiliar a viabilizar um processo interdisciplinar de Educação na escola (MEMORIAL 6). 
Neste ponto da pesquisa, buscou-se verificar se existia um movimento de interrelação entre a trajetória de formação - iniciada, em alguns casos, antes mesmo do ingresso na graduação e se deslocando em direção a pós-graduação - e as ações realizadas no trabalho, em seus distintos ambientes.

Com a análise dos memoriais verifica-se que um grupo significativo (12 sujeitos) não teve vínculos de trabalho assalariado durante a formação inicial. Encontramos sujeitos que trabalharam, mas em áreas distintas da formação. Por exemplo, M15 que iniciou seu ingresso no mundo do trabalho em uma empresa estadual de Água e Esgoto, antes e durante parte do período da graduação. Outro exemplo necessitou ingressar no mundo do trabalho durante a graduação em empresa de seguros (M18), área também discrepante em relação à formação, mas segundo seu depoimento, havia a necessidade de se manter enquanto estudava, pois não havia acesso à bolsa de estudos ou de estágio.

No caso da técnica em química, segue a graduação no curso de biologia. Entretanto, durante esse período se manterá trabalhando na profissão que exercia em uma empresa privada (M17).

Também existem relatos sobre o ingresso na profissão sem a formação esperada, como em M20 que cursa comunicação, mas vai lecionar na Educação Infantil, ou M18, que ingressa na docência sem ter cursado a Licenciatura.

Há, ainda, exemplos daqueles que na graduação trabalharam em áreas afins à carreira escolhida. Dentre os que cursaram no Ensino Médio o curso normal, há a manutenção da escolha pela educação através da opção pela licenciatura, além disso, permanecem no campo educacional exercendo o magistério durante a graduação (M2). Outros vão lecionar em suas áreas de estudo durante a graduação, através de convite de escolas privadas de Ensino Fundamental e Médio - M6, M11, M15 e M18 - e na Educação Infantil - M7. Um dos sujeitos vai trabalhar na área de jornalismo, o que se relaciona com o seu curso de graduação em Letras - M22.

Um número significativo de educadores apontaram para uma transição natural, isto é, recém-formados foram convidados e contratados pela iniciativa privada - M1, M4, M6, M13, M16, M18, M19 e M20. Outros seguiram o caminho da seleção pública para ingresso nas funções para as quais se qualificaram na graduação - M1, M2, M3, M4, M5, M7, M10, M11, M13, M14, M15, M16, M19, M21. Há os que permaneceram como convidados, desenvolvendo pesquisas na Universidade em parceria com a escola (M14) ou com outras instituições de pesquisa (M3).

Os sem vínculo empregatício (M8, M9, M12 e M22) recorrem a duas opções: vão permanecer na informalidade (M9 e M12) e, mais tarde, pleiteiam vaga na pósgraduação lato sensu (M12) e stricto sensu (M9) ou ingressam diretamente no mestrado, como M8 e M22, além de M5 - que passa para a rede estadual como professora, mas abre mão em virtude do ingresso imediato no curso de mestrado, em outro estado.

Durante o período de realização da(s) pós-graduação (ões) apenas uma educadora (M6) informou o afastamento integral do trabalho. Os demais mantiveram-se no exercício profissional ao mesmo tempo em que assistiam aulas, entregavam-se aos estudos e à pesquisa. $\mathrm{O}$ adiamento dos estudos também foi reportado: por estar muito envolvida com o movimento docente, a decisão de iniciar minha formação pósgraduada no mestrado foi por algumas vezes adiada (MEMORIAL 13).

Durante a pós-graduação e recém pós-graduados, alguns continuaram atuando nas mesmas funções: em relação à especialização (M7 e M12), ao mestrado (M2, M10 e M18) e ao doutorado (M2, M6 e M8). Houve também a ampliação da inserção no 
mundo do trabalho, incluindo novas funções e atividades durante a especialização (M4 e M16), durante o mestrado (M3, M6, M11, M12, M15, M16, M20) e o doutorado (M7, M8, M13, M15, M20 e M21).

Alguns trabalhadores, ao longo da pós-graduação, vão seguir por caminhos profissionais distintos daqueles apontados anteriormente. Alguns mudarão o tipo de atividade desenvolvida, como M1, que sairá da educação formal para a não formal, após pedir demissão de seu emprego público; M3, que ingressará na docência em instituição pública; duas educadoras que trilharão o inverso, isto é, sairão da docência no serviço público (M4) e no setor privado (M20) para a informalidade do trabalho no terceiro setor; M17 que sai da empresa privada onde atua como técnica em Química para a docência em instituição pública de ensino e, logo após, para o cargo de funcionária pública concursada de órgão ambiental. Outro exemplo, a educadora (M6) que sai do ensino em instituição privada para ao ensino público.

Outros educadores apenas mudarão suas condições de trabalho: mudarão da docência na Educação Básica para o Ensino Superior (após a especialização M13 ou o mestrado M15) e após o doutorado (M7 e M20).

Dos educadores ambientais analisados, alguns permaneceram como bolsistas e/ou em contratos sem vínculos permanentes de trabalho (M4, M5, M9, M14, M21, M22) durante o curso de mestrado.

Há aqueles que desenvolveram trabalho voluntário, geralmente em conexão com organizações do terceiro setor ou em grupos de estudo. Tais ações são variadas e envolvem atividades, como: alfabetização de adultos (somente durante a formação inicial - MEMO 4); realização de oficinas para professores de escolas públicas junto com seu grupo de estudos (experiência desenvolvida durante o primeiro ano da formação inicial - MEMO 6); movimento de defesa da Amazônia (trabalho desenvolvido junto ao movimento social no exterior durante o curso de mestrado MEMO 7), trabalhos comunitários e projetos educativos com comunidades (durante o Doutorado até a época de construção do memorial - MEMO 7); participação em organizações e coletivos ambientalistas diversos (desde a formação inicial - MEMO 8); componente do grupo de voluntários em ONG ambientalista (durante o mestrado MEMO 3), no grupo de trabalho de EA, também como membro da REBEA (da formação inicial até o ingresso no mestrado - MEMO 9); participação em grupo de estudo que colabora com o Movimento Sem Terra (do final da graduação ao mestrado MEMO 18); participação em Núcleo ligado ao movimento social (durante o mestrado) e de rede de educadores e escritores sobre experiências educacionais sustentáveis (doutorado - MEMO 20). Não foram consideradas como ações de voluntariado aquelas reportadas nos memoriais como eventos de formação, ligados à extensão ou à pesquisa acadêmica.

O trabalho voluntário contribuiu para o processo de formação e de inserção na profissão. Vejamos alguns destaques,

\footnotetext{
Minha atuação em movimentos sociais teve início quando morei em Nova York e desenvolvi trabalho voluntário junto à XXXX Network, uma organização não governamental que tinha por missão dar visibilidade $e$ apoio aos povos da Amazônia nos Estados Unidos. Dentre as atividades desenvolvidas destacaram-se a promoção da IV e V Semana da Amazônia e de campanhas, o acompanhamento de associados, coordenação de voluntários e a captação de recursos (MEMORIAL 7).
} 
Participo ativamente das comissões Miracatu, Itaguaré, Livro e Associação desde que foram criadas. Colaborei com a elaboração da "Metodologia de Análise das Regiões", escrevi boa parte dos textos de divulgação da ONG e fiz parte da comissão que escolheu a região do PIMA, quando tive a oportunidade de conhecer e pesquisar as regiões candidatas. Colaborei na elaboração e execução da última divulgação da ONG pelo Orkut, que fez dobrar o número de associados do XXXX (viva!) e escrevi também alguns textos sobre a ONG para o nosso site (MEMORIAL 9).

Existe uma relação explícita entre a formação e o exercício profissional que é mais do que meramente uma relação de causa e efeito. $\mathrm{O}$ memorial 13, aponta: "como em todos os cursos de formação de educadores as expectativas de formação são muito mais técnicas instrumentais do que crítico-reflexivas".

O ideário neoliberal prega a ideia de empregabilidade, que seria a condição potencial que o indivíduo deveria adquirir, por meio de formação e mudança ideológica de comportamento, para conseguir emprego.u seja, segundo esse pensamento, só não está empregado quem não possui determinadas condições. A especialização se insere nesta dinâmica, desde sua origem (LEITE DA SILVA, 2008, p.138).

Há um movimento em direção à pós-graduação, um processo de expansão agora, em direção ao doutorado - onde quanto maiores os desafios do mundo do trabalho maior é a necessidade de formação.

O mestrado me apontou uma nova perspectiva profissional. O trabalho no universo das ONGs (...), tornou-se mais qualificado e parece-me agora que a carreira universitária se adequa melhor ao meu perfil investigativo, de estudiosa assídua, interessada em escrever, lecionar e desenvolver projetos de extensão. Para que esta opção se concretize será fundamental cursar o doutorado (MEMORIAL 4).

Vista de outro ângulo, tal necessidade se assemelha à difundida ideia neoliberal de quanto mais formação (ou melhor, especialização), mais oportunidade no mercado de trabalho. Tais ideias se somam à perspectiva de competências, embasadas na noção de flexibilidade e de polivalência do educador, diretamente relacionadas com as políticas de formação em diversos espaços formativos - escolas, universidades, ONGs.

Um outro fator, relacionado diretamente a um grupo específico - o funcionalismo público - aponta a interferência das políticas de valorização da formação e de aumento salarial. Por fim, sendo a EA uma arena de lutas pela transformação socioambiental não é de se estranhar que os profissionais busquem o aprimoramento relatado em virtude dos amplos desafios enfrentados e da variedade de possibilidades em termos de atuação profissional no campo.

Pensando o duplo papel da educação ambiental, o político e o pedagógico, pensando em suas metas, nos obstáculos a serem enfrentados e nas perspectivas para a concretização de mudanças é importante apontar as diversas condições/contradições a que estão sujeitos os educadores ambientais em seus distintos loci de atuação profissional, interpretadas nesta pesquisa como fruto da precarização (LEHER; LOPES, 2008; LEITE, 2008; SOUZA, 2003) e da flexibilização (ANTUNES; SILVA, 2004) das relações de trabalho. Seguem alguns exemplos conclusivos a partir dos dados coletados nesta pesquisa: 
- Em parques e reservas florestais: flexibilização do trabalho a partir da terceirização ou subcontratação de funcionários, onde se constituem vínculos frágeis pela temporalidade restrita e incerteza de continuidade na função; baixa remuneração com aumento da jornada de trabalho; diversidade de atividades acumuladas etc.

- Nas ONGs: trabalhos de curto prazo (diaristas), onde os contratos de trabalho possuem tempo predeterminado; sujeitos a financiamentos temporários; intensificação e prolongamento da jornada de trabalho; salários abaixo da qualificação profissional; desconexão entre o pensar/criar e o fazer, pois tornam-se meros executores de projetos e tarefas elaboradas por outros etc.

- Na escola: tempo roubado da sala de aula para ações pontuais (por exemplo, em festejos comemorativos, pequenas campanhas etc), sem apoio institucional ou sem que as ações desenvolvidas façam parte de um projeto educacional que envolva toda a escola/comunidade; ações com pouco retorno em termos de transformação da realidade socioambiental e educacional; conflitos pela falta de uma formação inicial que dê conta do cotidiano e da realidade do sistema de ensino, principalmente público; manutenção da ruptura entre quem pensa (gestor) e quem faz (professor); falta de incentivo financeiro e carreira onde haja ascensão profissional; tendência uniformizadora do ensino; administração centralizadora etc.

- Na universidade: contratos temporários (bolsistas, substitutos, horistas etc.), com inexistência de vínculos (sem benefícios trabalhistas, sem garantia de continuidade no emprego etc); descontinuidade dos projetos desenvolvidos; políticas de financiamento cada vez mais restritivas; procura pela excelência baseada em padrões empresariais de performance acadêmica; demandas impostas por parceiros que substituem o Estado no financiamento das pesquisas; sem falar das exigências de formação contínua, ao longo de toda carreira, em vertentes diversas - competências científicas, relacionais, pedagógicas e de gestão - exigidas ao professor de carreira no ensino superior etc.

\section{Conclusões: as mudanças no trabalho do educador ambiental}

Retomando a centralidade da categoria trabalho, apontamos alterações nas relações de produção, transformações nas exigências do processo produtivo, relações que conformam a luta de classes, em um momento de avanço do capital monopolista. Na pesquisa apresentada, formas de organização e controle do trabalho se intensificam; amplia-se a capacidade de realizar trabalho, através do aumento da especialização e do uso do tempo. Verifica-se o relato de uma grande variedade de atividades profissionais, direcionadas a públicos diversos, onde ficam claros os movimentos no sentido da flexibilização, mobilidade, precarização e intensificação do trabalho do educador ambiental em suas múltiplas instâncias, que sofre com a desregulamentação, descentralização/autonomia e ampliação da apropriação do seu trabalho. O trabalho em ONGs e nas universidades (como substitutos) são exemplos recorrentes das condições de intensificação e flexibilização do trabalho.

A precarização da carreira, principalmente dos que se dedicam à educação básica sugere o que já foi averiguado em estudos diversos sobre a profissão docente (LEITÃO DE SOUZA, 2008; GATTI; BARRETO, 2009), os baixos salários e a sua consequência - o abandono da carreira docente. Nos dados de nossa pesquisa destaca-se a significativa migração da educação básica para o ensino superior, ou ainda, para outros postos de trabalho no serviço público. 
As formas particulares de reprodução da exploração do trabalho trazem consequências para a classe trabalhadora (ANTUNES; SILVA, 2004), como a sua heterogenização, complexificação e fragmentação, além da aceleração do trabalho em seus ritmos e processos (não há tempo livre, nem autorrealização), gerando o que consideram como subordinação real, cuja consequência é a subordinação formal do trabalho ao capital, à produção de mais-valia e mais-valia absoluta.

A partir do relato das memórias de educadores ambientais compreendemos os limites e as possibilidades formativas e do mundo do trabalho desses profissionais. É central supor que, ao pensarmos a formação de novas gerações de educadores ambientais, tenhamos em mente o papel que estes, vistos como intelectuais, possuem para aprofundarem a potência crítica da EA. Ao assumirem o comando intelectual de seus espaços de atuação, através da construção, organização e educação permanente, os educadores ambientais poderão trabalhar na esfera pedagógica e política de contestação do modelo socioambiental vigente, na esfera contra hegemônica.

\section{Referências}

ANTUNES, R. Os sentidos do trabalho: ensaios sobre a afirmação e a negação do trabalho. São Paulo: Boitempo, 2008.

ANTUNES, R.; SILVA, M. A. M. (Orgs.) O avesso do trabalho. São Paulo: Expressão Popular, 2004.

BAKHTIN, M. Marxismo e filosofia da linguagem. São Paulo: Martins Fontes, 2003.

BASTOS, M. H. C. Memoriais de professoras: reflexões sobre uma proposta. In: MIGNOT, A. C. V; CUNHA, M. T. S. (Orgs.) Práticas de memória docente. São Paulo: Cortez, 2003. p. 167183.

BRASIL. Constituição da República Federativa do Brasil de 1988. Disponível em: <http://www.planalto.gov.br/ccivil_03/constituicao/ConstituicaoCompilado.htm>. Acesso em: 17 nov. 2014.

BRASIL. Casa Civil. Lei $n^{\circ}$ 9795, de 27 de abril de 1999. Dispõe sobre a educação ambiental , institui a Política Nacional de Educação Ambiental e dá outras providências. Disponível em: <http://www.planalto.gov.br/ccivil_03/leis/19795.htm>. Acesso em: 17 nov. 2014.

BRASIL. Ministério da Educação. Secretaria de Educação Básica. Educação Ambiental. Série Cadernos Pedagógicos Mais Educação, n. 3. Brasília: Secretaria de Educação Básica do Ministério da Educação, s/data. 60 p. Disponível em:

$<$ http://www.google.com.br/url?sa=t\&rct=j\&q=\&esrc=s\&source=web\&cd=1\&ved=0CB8QFjA A\&url=http\%3A\%2F\%2Fportal.mec.gov.br\%2Findex.php\%3Foption\%3Dcom_docman\%26tas k\%3Ddoc_download\%26gid\%3D12332\%26Itemid\%3D\&ei=wF5uVOXILYSagwT5uITwDA\& usg=AFQjCNHXUdT5yWT-6hTdwO3MtWdoygVDrg\&bvm=bv.80185997,d.eXY>. Acesso em: 10 ago. 2013.

GATTI, B. A.; BARRETO, E. S. de S. Professores do Brasil: impasses e desafios. Brasília: UNESCO, 2009. 
GRAMSCI, A. Cadernos do Cárcere. 3 ed. Rio de Janeiro: Civilização Brasileira, 2004. (Vol. I).

GUIMARÃES, M. A formação de educadores ambientais. São Paulo: Papirus, 2004.

LEHER, R.; LOPES, A. Trabalho docente, carreira, autonomia universitária e mercantilização da educação. In: SEMINÁRIO INTERNACIONAL REDESTRADO - Nuevas Regulaciones en América Latina, 7, Buenos Aires, 2008. Anais... Buenos Aires: Rede Latinoamericana de Estudos sobre Trabalho Docente, 2008. p.1-26. CD-ROM.

LEITÃO DE SOUZA, A. L. Organização, resistência e profissionalização do (a) trabalhador (a) docente frente aos novos marcos regulatórios da política educacional no Brasil. In:

SEMINÁRIO INTERNACIONAL REDESTRADO - Nuevas Regulaciones en America Latina, 7, Buenos Aires, 2008. Anais... Buenos Aires: Rede Latinoamericana de Estudos sobre Trabalho Docente, 2008. p.1-16. CD-ROM.

LEITE, M. de P. O trabalho e suas configurações: conceitos e realidades. In: ENCONTRO ANUAL DA ANPOCS, 32, Caxambu, 2008. Anais... Caxambu: Associação Nacional de PósGraduação e Pesquisa em Ciências Sociais, 2008. p.1-34. CD-ROM.

LEITE DA SILVA, F. A. A formação do (a) educador (a) ambiental nos programas de pósgraduação lato sensu das instituições de ensino superior do estado do Rio de Janeiro: uma análise crítica. 2008. 163f. Dissertação (Mestrado em Educação) - Universidade Federal do Rio de Janeiro. Rio de Janeiro, 2008.

LUKÁCS, G. As bases ontológicas do pensamento e da atividade do homem. Temas de Ciências Humanas, São Paulo: [s.n.], 1978. Disponível em:

<http://www.giovannialves.org/Bases_Luk\%E1cs.pdf >. Acesso em: 10 mai. 2007.

MARX, K. O capital. São Paulo: Abril Cultural, 1982. (Vol. I).

MARX, K.; ENGELS, F.A Ideologia Alemã. Teses sobre Feuerbach. São Paulo: Centauro, 2005.

MIGNOT, A. C.V. Em busca do tempo vivido: autobiografias de professoras. In:

CUNHA, M. T. S. (Orgs.) Práticas de memória docente. São Paulo: Cortez, 2003. p.135-148.

REDE CEAS. Portal da Rede Brasileira de Centros de Educação Ambiental. Listagem de CEAs Brasil, 2004. Disponível em: http://www.redeceas.esalq.usp.br/base.htm Acesso em: 21 de nov. 2014.

SANCHEZ, C. Os nós, o laço e a rede: considerações sobre a institucionalização da Educação Ambiental no Brasil. 2008. 182 f. Tese (Doutorado em Educação) - Pontifícia Universidade Católica. Rio de Janeiro, 2008.

SENNETT, R. A corrosão do caráter: as consequências pessoais do trabalho no novo capitalismo. Rio de Janeiro: Record, 2004.

SILVA, M. das G. Sustentabilidade Ambiental e (in) sustentabilidade social. In: MOTA, A. E. (Org.). Desenvolvimento e construção de hegemonia: crescimento econômico e reprodução da desigualdade. São Paulo: Cortez, 2012. p.105-124.

SOUZA, D. B. O contrato precário de trabalho e a degradação do ensino superior público 
brasileiro. Rev. Espaço Acadêmico, Maringá, Ano II, n. 23, s/p, abr. 2003. Disponível em: <http://www.espacoacademico.com.br/023/23csouza.htm >. Acesso em: 17 nov. 2014.

VÁZQUEZ, A. S. Filosofia da práxis. 4 ed. Rio de Janeiro: Paz e Terra, 1990.

Versão recebida em 12/10/2013

Aceite em 25/08/2014 